\title{
ANÁLISE DO ABASTECIMENTO HÍDRICO DE BELO HORIZONTE E REGIÃO METROPOLITANA: UMA ABORDAGEM POR MEIO DE DINÂMICA DE SISTEMAS
}

ANALYSIS OF BELO HORIZONTE AND METROPOLITAN REGION

WATER SUPPLY: AN APPROACH THROUGH SYSTEM DYNAMICS

\section{Rafaella Otoni}

Miranda de Freitas $\odot$

Mestre em Engenharia e Gestão de Processos e Sistemas pelo Instituto de Educação Tecnológica (IETEC). Engenheira civil pela Pontifícia Universidade Católica de Minas Gerais (PUC-Minas) Belo Horizonte (MG), Brasil.

\section{Gisele Tessari Santos}

Doutora em Engenharia Agrícola pela Universidade Federal de Viçosa (UFV). Mestre em Engenharia de Produção pela Universidade Federal de Minas Gerais (UFMG). Professora do curso de Mestrado no IETEC e do curso de Engenharia de Produção na Faculdade de Economia e Finanças (IBMEC) Belo Horizonte (MG), Brasil.

\section{Eduardo Trindade Bahia (0)}

Doutor em Ciências Del Mar pela Universidade Politécnica da Catalunha. Mestre em Engenharia Agrícola pela UFV. Professor do curso de Mestrado no IETEC Belo Horizonte (MG), Brasil.

\section{Endereço para correspondência:}

Rafaella Otoni Miranda de Freitas - Rua do Ouro, 828, apto. 201 - Serra - CEP 30220-000 Belo Horizonte (MG), Brasil E-mail: rafaellaotoni@hotmail.com

Recebido em: 11/08/2017

Aceito em: 30/05/2018

\section{RESUMO}

A água é um recurso natural essencial para a vida no planeta. Nesse contexto, o trabalho teve como objetivo aplicar a metodologia de dinâmica de sistemas à gestão de recursos hídricos da Região Metropolitana de Belo Horizonte visando prever cenários de ofertas e demandas hídricas para os próximos 15 anos. O principal diferencial do modelo proposto foi, além de considerar os oito sistemas que abastecem a região de maneira integrada, identificar os momentos e locais em que ocorrem os colapsos hídricos. Validou-se o modelo utilizando dados históricos, e simularam-se três cenários para verificar o comportamento do sistema hídrico adiante da variação de oferta e demanda. A fim de analisar quantitativamente a vulnerabilidade dos recursos hídricos ao longo do tempo, calculou-se o índice de sustentabilidade. Constatou-se que existem sistemas que já possuem déficit hídrico desde 2016 e sistemas passíveis de colapso que devem ser analisados cuidadosamente pela gestão de recursos hídricos da região.

Palavras-chave: gestão de recursos hídricos; modelo de simulação; colapso hídrico; índice de sustentabilidade.

\section{ABSTRACT}

Water is an essential natural resource for life on the planet. In this context, the objective of this work was to apply the system dynamics methodology to the hydric resources management of Belo Horizonte metropolitan area to predict scenarios of hydric supplies and demands for the next 15 years. The main differential offered by this proposed model was, besides considering the eight systems that supply the region in an integrated way, to identify the moments and locals in which the hydric collapses occur. The model was validated using historical data, and three scenarios were simulated to verify the hydric collection system's behavior in concern to a variation of supply and demand. Then, the sustainability index was calculated to analyze the vulnerability of the hydric resources along the period quantitatively. It was concluded that there are systems that already have a hydric deficit since 2016 and systems that are probable to collapse, so they have to be carefully examined by the region hydric resource management.

Keywords: management of water resources; simulation model; water collapse; sustainability index. 


\section{INTRODUÇÃO}

A água é um recurso natural essencial para a vida no planeta, sendo um dos principais constituintes de todos os organismos vivos. Sua escassez impacta diretamente no meio ambiente, na sobrevivência de todos os seres vivos, além de afetar a economia, ameaçando sua estabilidade e manutenção (GOULART et al., 2011; KELMAN, 2015; WEI et al., 2016).

De acordo com Rodriguez (1998), no Brasil, até 1920 não houve registros de problemas advindos da falta de água. Já entre os anos de 1970 e 80 a abundância desse recurso natural passou a ser ameaçada pela própria população, que não o utilizava de forma adequada, somado à distribuição desigual em território brasileiro apesar de, segundo a Agência Nacional de Águas (ANA, 2016), o país possuir cerca de $12 \%$ de toda a água superficial do mundo. Segundo Feil e Tucci (2014), é necessário incentivar comportamentos que promovam a conservação da água, tais como hábitos positivos de consumo, prestação de informações à sociedade, realimentação de informações sobre o uso e normas sociais.

Conforme a Agência Nacional de Águas (ANA, 2016), Minas Gerais é o estado brasileiro com maior número de municípios (853) e possui população urbana com cerca de 16,7 milhões de habitantes. A Região Metropolitana de Belo Horizonte (RMBH) é composta de 34 cidades e concentra $28,7 \%$ da população do estado. Segundo a Companhia de Saneamento de Minas Gerais (COPASA, 2016), a região está sofrendo com a escassez de água desde 2013 por causa das estações chuvosas mais escassas dos últimos anos. Aliando a falta de chuva ao consumo crescente e a perdas que passam de $40 \%$ na distribuição de água, os reservatórios do Sistema Paraopeba, por exemplo, também atingiram um nível 54,5\% menor na estação chuvosa entre 2014 e 2015 em comparação com o período anterior. O volume médio mensal do sistema foi de $33,6 \%$ da capacidade total entre outubro de 2014 e março de 2015, enquanto na temporada anterior ficou em 73,8\% (COPASA, 2015).

De acordo com Wang et al (2015), como resposta às necessidades e mudanças enfrentadas na área de gestão de recursos hídricos, fazem-se necessários o desenvolvimento e a utilização de ferramentas com sólida base científica que apoiem as tomadas de decisão. Para Yang et al. (2014); Ayala, Okumura e Kim (2014); e Wang e Davies (2018), o desenvolvimento urbano,o planejamento e a gestão do uso da água tratam de um sistema complexo de comportamento dinâmico. Portanto, para melhor compreendê-lo, é preciso ferramentas atreladas à dinâmica de sistemas (DS).

A DS é uma metodologia proposta inicialmente por Jay W. Forrester em 1950 que permite quantificar a relação entre cada variável, estabelecer um sistema integrado de equações e, em seguida, prever resultados que ajudem a compreender as causas estruturais do comportamento de um sistema, avaliando como as ações em diferentes partes afetam o comportamento do todo. Portanto, trata-se de uma técnica que permite, basicamente, a análise de um conjunto de elementos inter-relacionados, pois qualquer alteração em determinado elemento afeta todo o conjunto. Cabe ressaltar que a modelagem por meio de DS segue os passos gerais de qualquer modelagem, que são conceitualização, formulação do modelo, teste, validação e implementação (GARCIA, 2003; YANG et al., 2014; DOMINGOS; POLITANO; PEREIRA, 2015).

Essa metodologia vem sendo aplicada em diversas áreas. Mula et al. (2013), por exemplo, utilizaram a DS para analisar o planejamento de transportes em uma cadeia de suprimentos multiproduto e multiperíodo do setor automotivo; Li e Madnick (2015) aplicaram-na para avaliar a implementação de um sistema de arquitetura orientada a serviços em diferentes cenários e organizações; Qi e Chen (2015) desenvolveram um modelo de DS para analisar a seleção, a permanência e a perda de excelentes alunos em uma universidade da China; Hovi et al. (2017) utilizaram-na para verificar o ciclo de vapor em uma caldeira comercial; e Salim et al. (2016) empregaram a DS para estimar a probabilidade de um colapso em cascata considerando o efeito da faIha oculta em um sistema de proteção.

De acordo com Fernandéz, Suárez e Pérez (2007) e Chen e Wei (2014), a modelagem e simulação por meio de DS também são extremamente compatíveis a problemas que envolvem processos físicos, químicos e biológicos, de modo que a torna ideal para representar sistemas ecológicos. Os autores modelaram e simularam o balanço hídrico da bacia do Rio Pamplonita, localizado ao norte de Santander, na Colômbia. O modelo proposto por eles considera como variável de entrada o fluxo consolidado de todas as nascentes que alimentam 
as sub-bacias e como variáveis de saída o fluxo ecológico necessário para a manutenção do Rio Pamplonita, a demanda dos vilarejos próximos às sub-bacias e a demanda da cidade Pamplona, que leva em conta o consumo per capita e a dinâmica populacional dada pelas taxas de mortalidade e expectativa de vida.

Goulart et al. (2011) também utilizaram a DS para analisar o sistema de bacias hidrográficas. Eles pesquisaram, em seu modelo, as bacias hidrográficas dos rios Piracicaba, Capivari e Jundiaí, localizadas em São Paulo, e tiveram como objetivo prever, em cenários de oferta e de demanda hídrica, se poderia haver ocorrência de colapso no sistema de captação hídrica por déficit de oferta. Diferentemente do que foi proposto por Fernandéz, Suárez e Pérez (2007), esse modelo abrange também os lançamentos de efluentes que retornam à bacia principal e os somam à oferta total disponível, além de dividir a demanda em setores urbano, industrial, rural e outros, tornando-o mais realista.
Já Simonovic e Rajasekaram (2004) desenvolveram um modelo de gestão integrada dos recursos hídricos para - Canadá denominado de Canada Water, empregando também a metodologia de simulação de DS. O modelo, comparado aos de Fernandéz, Suárez e Pérez (2007) e Goulart et al. (2011), é bem mais complexo, já que integra a quantidade e a qualidade da água com sete setores que impulsionam o desenvolvimento econômico: população, desenvolvimento agrícola, produção de alimentos, investimento de capital, geração de energia, uso de recursos não renováveis e poluição.

Diante do exposto, o presente trabalho tem como propósito aplicar a metodologia de DS à modelagem do sistema de recursos hídricos de Belo Horizonte e demais cidades que compõem sua região metropolitana e que são atendidas por bacias hidrográficas, integral ou parcialmente, visando avaliar seu desempenho atual e prever cenários de ofertas e demandas hídricas para os próximos 15 anos.

\section{MATERIAIS E MÉTODOS}

\section{Caracterização da área escolhida}

O Rio São Francisco possui aproximadamente $2.800 \mathrm{~km}$ de extensão, e a sua bacia drena uma área de $639.219 \mathrm{~km}^{2}$. A RMBH enquadra-se nas bacias hidrográficas do Rio das Velhas e do Rio Paraopeba, que, por sua vez, integram a Bacia do Rio São Francisco.

Por meio dessas duas bacias principais, a RMBH é abastecida por oito sistemas produtores que trabalham de forma integrada: Ibirité, Barreiro, Catarina, Morro Redondo, Rio das Velhas, Rio Manso, Vargem das Flores e Serra Azul. Além desses sistemas, existem mananciais superficiais e poços artesianos que contribuem para o atendimento de algumas cidades da $\mathrm{RMBH}$, porém tal estudo não é o foco deste trabalho. Assim sendo, as cidades da RMBH que, de acordo com a ANA (2016), possuem abastecimento hídrico exclusivamente por mananciais e poços não foram consideradas no modelo proposto. São elas: Baldim, Capim Branco, Confins, Florestal, Itaguara, Itatiaiuçu, Jaboticatubas, Lagoa Santa, Matozinhos, Nova União, Rio Acima, Rio Manso, São José da Lapa e Taguaraçu de Minas.

\section{Modelo de dinâmica de sistemas para abastecimento hídrico}

\section{Modelo de dinâmica de sistemas para o Sistema Integrado Rio das Velhas}

Para a apresentação do modelo desenvolvido neste trabalho, tomar-se-á como exemplo apenas o Sistema Integrado do Rio das Velhas (SIRV). Assim, pode-se observar na Figura 1 o seu diagrama de fluxo.

No modelo apresentado, cada variável, sendo ela de fluxo, de estoque ou auxiliar, tem uma equação relacionada que permite o cálculo do balanço hídrico do sistema e dá origem ao seu comportamento di- nâmico. As variáveis de fluxo como AfluenteRV e RV Entrada 1 são funções do tempo responsáveis pelas variações nas variáveis de estoque. Já as variáveis de estoque como Sistema Rio das Velhas e RV Abastecimento 1 representam acúmulos e só se alteram em função das variáveis de fluxo. As variáveis auxiliares e constantes, tais como Demanda total Rv e Perdas $R A P$, são parâmetros e permitem melhor visualização dos aspectos que afetam o comportamento dos fluxos 
(GARCIA, 2003). As equações associadas às variáveis do modelo de DS desenvolvido para o SIRV (Figura 1) são descritas a seguir.

A vazão de água captada no rio varia de acordo com a demanda da região, tendo como limite a capacidade máxima de produção do afluente, que considera a sazonalidade e os limites de transporte e a reservação no sistema. Dessa maneira, o volume de água captado no SIRV (afluente RV) pode ser expresso pela Equação 1:

AfluenteRV $=M I N\left\{\begin{array}{l}\text { Capacidade máx de prod. RV } \\ \text { Demanda total } \mathrm{RV} \times \\ (1+\text { Água retida } \mathrm{ETA})\end{array}\right.$

Em que:

Capacidade máx de prod. RV = a capacidade máxima de produção do SIRV ( $\mathrm{m}^{3} /$ dia);

Demanda total RV = demanda total do SIRV $\left(\mathrm{m}^{3} / \mathrm{dia}\right)$; Água retida $\mathrm{ETA}=$ a água retida na estação de tratamento de água (ETA) para limpeza $\left(\mathrm{m}^{3} / \mathrm{dia}\right)$.
De acordo com o modelo desenvolvido, nem toda água captada é enviada para suprir a demanda da região; uma pequena parcela é retida na ETA para limpeza dos filtros e demais equipamentos. Portanto, o volume de água ofertado para atender à demanda (RV Entrada 1) é obtido pela Equação 2:

RVEntrada1 $=\left\{\begin{array}{l}\text { Afluente } \mathrm{RV}-(\text { Demanda total } \mathrm{RV} \times \\ \text { Água retida ETA) if } \\ \text { Demanda total } \mathrm{RV} \leq \text { Capacidade } \\ \text { máx de prod. } \mathrm{RV} \\ \text { Afluente } \mathrm{RV}-(\text { Capacidade máx } \\ \text { de prod. } \mathrm{RV} \times \text { Água retida ETA }) \text { if } \\ \text { Demanda total } \mathrm{RV}>\text { Capacidade } \\ \text { máx de prod. } \mathrm{RV}\end{array}\right.$

Após ser tratada na ETA, toda a água disponível segue em direção às cidades para atendimento às demandas. A saída parcial para atendimento à primeira demanda do SIRV, referente a Raposos (rVRAP), é expressa pela Equação 3:

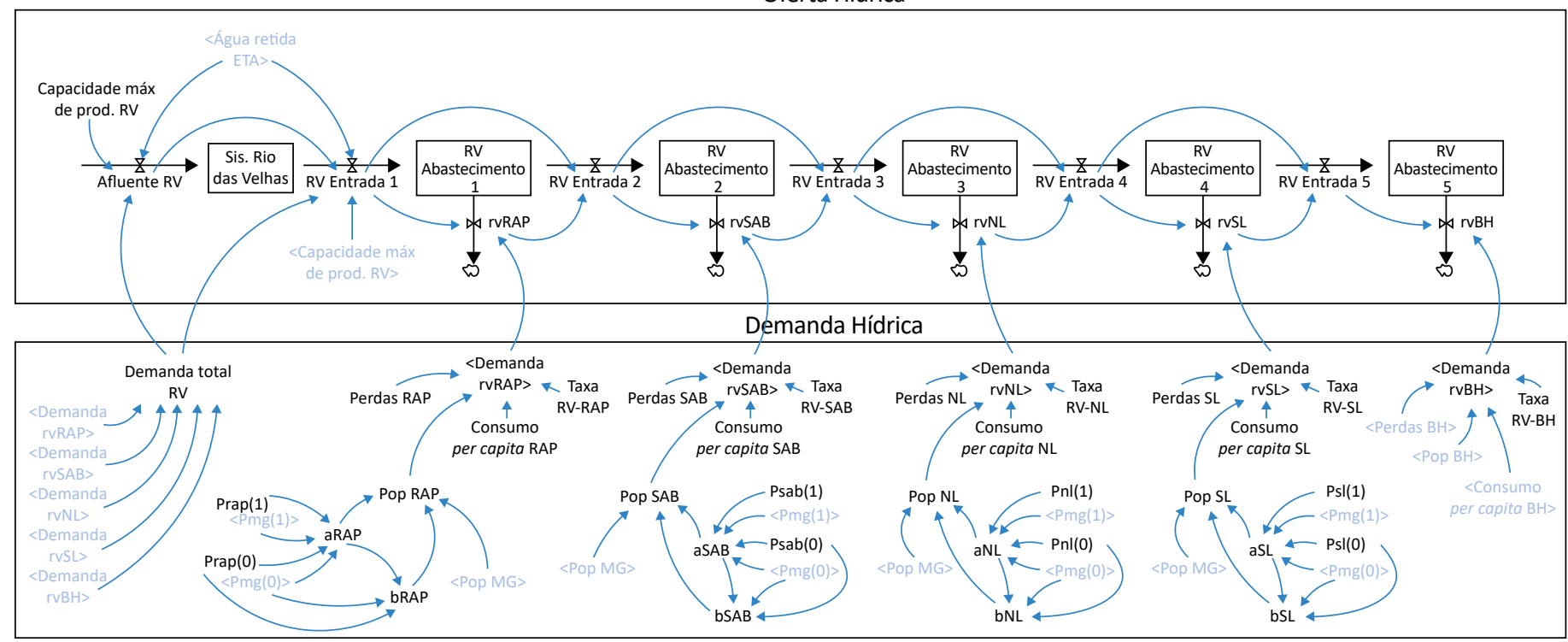

ETA: estação de tratamento de água; RV: Rio das Velhas; rvRAP: saída parcial do Sistema Rio das Velhas para atendimento da demanda hídrica de Raposos; rvSAB: saída parcial do Sistema Rio das Velhas para atendimento da demanda hídrica de Sabará; rvNL: saída parcial do Sistema Rio das Velhas para atendimento da demanda hídrica de Nova Lima; rvSL: saída parcial do Sistema Rio das Velhas para atendimento da demanda hídrica de Santa Luzia; rvBH: saída parcial do Sistema Rio das Velhas para atendimento da demanda hídrica de Belo Horizonte; RAP: Raposos; Pop: População; aRAP: coeficiente de proporcionalidade do incremento da população de Raposos em relação ao incremento da população de Minas Gerais; bRAP: o coeficiente linear de correção da população de Raposos; NL: Nova Lima; SL: Santa Luzia; BH: Belo Horizonte.

Figura 1 - Modelo de dinâmica de sistemas para o Sistema Integrado do Rio das Velhas (SIRV). 
$r V R A P=\left\{\begin{array}{l}\text { Demanda rVRAP if RV Entrada } 1 \geq \\ \text { Demanda rVRAP } \\ \text { RV Entrada } 1 \text { if RV Entrada } 1< \\ \text { Demanda rVRAP }\end{array}\right.$

Em que:

RV Entrada 1 = a oferta de água disponível para atendimento à cidade 1 (Raposos) ( $\mathrm{m}^{3} / \mathrm{dia}$ );

Demanda rvRAP = a demanda urbana de água de Raposos ( $\left.\mathrm{m}^{3} / \mathrm{dia}\right)$.

Na Figura 1, as saídas parciais ( $r v S A B, r v N L, r v S L$ e $r v B H$ ) para atendimento às demais demandas do SIRV seguem o mesmo princípio já descrito.

Os estoques parciais (RV Abastecimento 1, RV Abastecimento 2, RV Abastecimento 3, RV Abastecimento 4 e $R V$ Abastecimento 5) posteriores ao atendimento às demandas do SIRV permanecem constantemente zerados, uma vez que, após o atendimento do primeiro município, a água restante segue em direção às próximas cidades, não ficando estocada no interior do sistema. $\mathrm{O}$ estoque parcial referente a Raposos (RV Abastecimento 1) é calculado pela Equação 4:

RV Abastecimento $1_{(t)}=$ RV Abastecimento $1_{(t-d t)}+$ RV Entrada 1 - rVRAP - RV Entrada 2)dt

\section{Em que:}

$\mathrm{t}=$ tempo;

$\mathrm{dt}=$ tamanho do passo de tempo.

Após o abastecimento de cada cidade, verifica-se se há volume de água disponível remanescente para prosseguir no sistema. Caso exista, esse volume é enviado para atendimento da demanda do próximo município do sistema. Porém, caso não haja mais água disponível, logicamente não é enviado nenhum volume para a sequência do sistema. A vazão referente ao volume de água remanescente após o atendimento à demanda da primeira cidade do SIRV (RV Entrada 2), aqui Raposos, é mensurada pela Equação 5:
RV Entrada $2=\left\{\begin{array}{l}\text { RV Entrada } 1-r V R A P \text { if } \\ R V \text { Entrada } 1 \geq \operatorname{rVRAP} \\ 0 \text { if RV Entrada } 1<\text { Demanda rVRAP }\end{array}\right.$

Em que:

RV Entrada 1 = a oferta de água disponível para atendimento à cidade 1 - Raposos ( $\left.\mathrm{m}^{3} / \mathrm{dia}\right)$;

rVRAP = a demanda urbana de Raposos $\left(\mathrm{m}^{3} / \mathrm{dia}\right)$.

Na Figura 1, os volumes de água remanescentes parciais ( $R V$ Entrada 3, RV Entrada 4 e RV Entrada 5) relativos ao atendimento às demais demandas do SIRV seguem o mesmo princípio descrito anteriormente.

O abastecimento hídrico de cada cidade por um sistema específico equivale à sua demanda hídrica parcial referente àquele sistema. Cabe lembrar que cada município normalmente é abastecido por mais de um sistema. Essa demanda é calculada considerando o consumo médio per capita, a população residente, as taxas de perda de água que ocorrem na distribuição e a porcentagem da demanda que é abastecida pelos sistemas produtores. Assim, a Equação 6 mede a demanda hídrica da primeira cidade atendida pelo SIRV, Raposos (Demanda rvRAP):

Demanda rvRAP $=\frac{\begin{array}{c}\text { Consumo per capita RAP } \times \\ \text { Pop RAP } \times \text { Taxa "RV-RAP" }\end{array}}{1-\text { Perdas RAP }}$

Em que:

Consumo per capita RAP = o consumo médio per capita de Raposos ( $\mathrm{m}^{3} /$ habitantes por dia);

Pop Rap = população de Raposos (habitantes);

Taxa RV-RAP = taxa de atendimento à demanda total de Raposos pelo SIRV (\%);

Perdas RAP = perdas na distribuição em Raposos (\%).

Na Figura 1, as demandas hídricas (Demanda rvSAB, Demanda rVNL, Demanda rvSL e Demanda rVBH) referentes às demais cidades atendidas pelo SIRV seguem o mesmo princípio.

A equação 7 resulta na demanda total atendida pelo SIRV (Demanda total RV), sendo a soma das deman- 
das hídricas parciais de todas as cidades atendidas pelo sistema:

$$
\begin{aligned}
& \text { Demanda rvRAP }+ \\
& + \text { Demanda rvSAB }+ \\
\text { Demanda total } \mathrm{RV}= & + \text { Demanda rvNL }+ \\
& + \text { Demanda rvSL }+ \\
& + \text { Demanda } r \mathrm{BH}
\end{aligned}
$$

\section{Em que:}

Demanda rVRAP, Demanda rVSAB, Demanda rVNL, Demanda rvSL e Demanda rVBH = demandas urbanas de Raposos, Sabará, Nova Lima, Santa Luzia e Belo Horizonte, respectivamente, atendidas pelo $\operatorname{SIRV}\left(\mathrm{m}^{3} / \mathrm{dia}\right)$.

Para o cálculo da estimativa populacional de cada cidade abastecida pelo sistema (PopRAP, PopSAB, PopNL, PopSL e PopBH), utilizou-se a metodologia do Instituto Brasileiro de Geografia e Estatística (IBGE) (MADEIRA; SIMÕES, 1972). Dessa maneira, a população de Raposos (Pop RAP) é expressa pelas equações 8, 9 e 10:
Pop RAP $=($ aRAP $\times$ Pop MG $)+b R A P$

$$
\operatorname{aRAP}=\frac{\operatorname{Prap}(1)-\operatorname{Prap}(0)}{\operatorname{Pmg}(1)-\operatorname{Pmg}(0)}
$$

bRAP $=\operatorname{Prap}(0)-(a R A P \times P m g(0))$

\section{Em que:}

aRAP = coeficiente de proporcionalidade do incremento da população de Raposos em relação ao incremento da de Minas Gerais (adimensional);

bRAP = o coeficiente linear de correção (hab.);

Pop MG = a população de Minas Gerais (hab.);

Prap(1) = a população de Raposos conforme o censo de 2010 (hab.) (IBGE, 2010);

$\operatorname{Prap}(0)=$ a população de Raposos de acordo com o censo de 2000 (hab.) (IBGE, 2000);

$\operatorname{Pmg}(1)=$ a população de Minas Gerais pelo censo de 2010 (hab.) (IBGE, 2010);

$\operatorname{Pmg}(0)=$ a população de Minas Gerais em conformidade com o censo de 2000 (hab.) (IBGE, 2000).

\section{Integração dos sistemas de bacias hidrográficas no modelo proposto}

Os oito sistemas que abastecem a RMBH são integrados fisicamente por meio de reservatórios de distribuição, subadutoras e redes alimentadoras. As ofertas de água de diferentes sistemas chegam a esses reservatórios e são armazenadas neles antes de serem distribuídas para atender à demanda hídrica da região. Esse é o caso dos sistemas Vargem das Flores, Serra Azul e Rio Manso, que compõem o Sistema Integrado do Paraopeba e o SIRV, composto dos sistemas Rio das Velhas e Morro Redondo. Além disso, a integração dos sistemas no modelo de DS proposto também ocorre quando uma mesma cidade é abastecida por mais de um sistema simultaneamente, o que, de fato, ocorre na maioria dos municípios estudados da RMBH.

\section{Dados de entrada}

O modelo proposto para o balanço hídrico dos oito sistemas produtores de água da RMBH foi simulado por meio do software Vensim (VENTANA SYSTEM, 2016) para o período de 2016 a 2030. O método de integração escolhido para simulação foi o método de Euler, e o passo de tempo $(d t)$ foi de um dia.
A fim de representar a integração no modelo proposto, considerou-se a porcentagem das demandas de cada cidade da região que é atendida pelos sistemas individualmente. Esses dados foram fornecidos pela ANA (2016).

Pode-se observar, na Figura 2, os diferentes sistemas que ofertam água a fim de atender à demanda de todas as cidades da RMBH abrangidas no modelo. Assim, de acordo com a figura, constata-se que a demanda hídrica da cidade de Contagem, por exemplo, é atendida pela água vinda dos sistemas Vargem das Flores, Serra Azul e Rio Manso.

Os dados de entrada do modelo utilizados neste trabalho são originários de fontes de informação secundária, como: ANA, Copasa, IBGE, Sistema Nacional de Informações sobre Saneamento (SNIS) e Prefeitura de Belo Horizonte (PBH). Também foram usados dados de ordem primária, como os de estimativa populacional de todas as cidades estudadas 
calculadas neste trabalho, com base na mesma metodologia aplicada atualmente pelo IBGE (equações 8,9 e 10). Os consumos per capita médios e as perdas na distribuição em todas as cidades são referentes ao ano de 2015, dado mais atual divulgado pelo SNIS (BRASIL, 2016). Já a taxa de água retida na ETA foi $3 \%$, já que, de acordo com a literatura encontrada, a taxa para limpeza da ETA varia de 2 a 4\% (PLANO MUNICIPAL DE SANEAMENTO DE SÃO PAULO, 2009).

\section{Indicador de vulnerabilidade dos recursos hídricos}

A fim de analisar quantitativamente e comparar os resultados das simulações, foi calculado um índice que diz respeito à vulnerabilidade dos recursos hídricos ao longo do tempo, o índice de sustentabilidade (IS) proposto por Xu et al. (2002). O IS define o possível déficit de água ao se comparar a oferta e a demanda correspondente na mesma região. Dessa maneira, pode ser expresso conforme a Equação 11:

$I S=\left\{\begin{array}{l}(S-D) / S \text { if } S>D \\ 0 \text { if } S \leq D\end{array}\right.$
Em que:

$\mathrm{S}=$ a oferta de água disponível na região $\left(\mathrm{m}^{3} / \mathrm{dia}\right)$;

$\mathrm{D}=$ demanda de água da região $\left(\mathrm{m}^{3} / \mathrm{dia}\right)$.

Valores do IS maiores que 0,2 correspondem à baixa ou a nenhuma tensão de abastecimento de água, o que implica que a demanda de água é menor ou igual a $80 \%$ da oferta potencial. Em contrapartida, os valores de IS menores que 0,2 refletem condições vulneráveis. Ou seja, a demanda de água é maior que $80 \%$ do potencial de abastecimento da região.

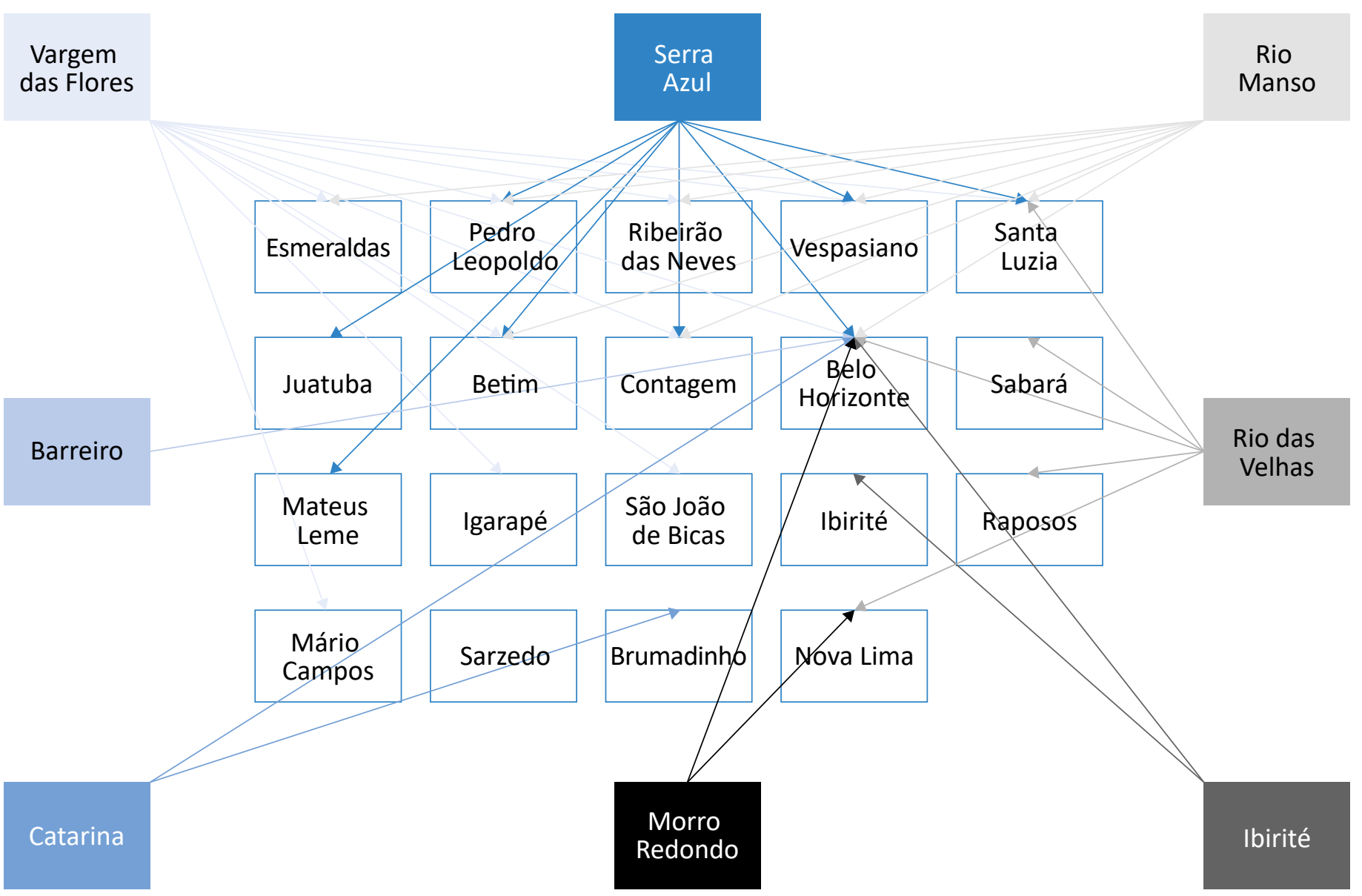

Figura 2 - Integração dos sistemas de abastecimento hídrico da Região Metropolitana de Belo Horizonte (RMBH). 
Valores de IS iguais a zero indicam oferta de água insustentável. Isto é, a demanda de água já é igual ou

\section{Validação do modelo}

A fim de validar o modelo proposto, consideraram-se as cinco maiores e mais significativas cidades da $\mathrm{RMBH}$ abastecidas pelo sistema integrado. $\mathrm{O}$ objetivo desta etapa foi verificar o quão próximo o comportamento do sistema simulado está da realidade atual e histórica. Para tanto, levou-se em conta a demanda hídrica histórica das cidades de Belo Horizonte, Contagem, Betim, Ribeirão das Neves e Ibirité de 2002 a 2015, e comparou-se tal demanda com a demanda dessas regiões geradas por meio da simulação do modelo proposto para o mesmo período. Cabe ressaltar que o volume de água produzido no modelo aqui exposto é igual à demanda hídrica somada à perda na distribuição do sistema.

A fim de verificar quão eficaz o modelo utilizado é para predizer o comportamento do sistema real, uti- excede todos os recursos hídricos locais disponíveis (XU et al., 2002).

lizou-se como medida de erro o erro relativo percentual (e), que representa a diferença relativa entre os valores previstos pelo modelo e os valores reais de demanda hídrica no sistema integrado. Dessa maneira, o erro relativo percentual foi calculado por meio da Equação 12:

$e=\left[\frac{X r, i-X s, i}{X r, i}\right] \times 100 \%$

Em que:

$\mathrm{Xr}, \mathrm{i}=$ as vazões reais produzidas pelos sistemas;

$\mathrm{Xs}, \mathrm{i}=$ as vazões produzidas simuladas pelos sistemas $i$ no modelo proposto.

\section{RESULTADOS E DISCUSSÃO}

Os resultados da validação do modelo proposto, conforme a Equação 12, apontam que as demandas hídricas reais e simuladas para as cinco cidades possuem comportamento semelhante nos 13 anos analisados. O maior erro encontrado foi de 8,31\% em 2015, na cidade de Ibirité. Já em 2012, em Ribeirão das Neves, foi observado o menor erro relativo, com valor de $0,02 \%$. 0 erro relativo médio durante o período analisado foi de $0,97 \%$ em Belo Horizonte, 1,1\% em Contagem,
1,4\% em Betim, 1,39\% em Ribeirão das Neves e 1,51\% em Ibirité.

Diante dos resultados apresentados, pode-se concluir que o modelo proposto é válido para predizer o comportamento do sistema hídrico real, já que o maior erro relativo médio encontrado para o período simulado nas cinco cidades mais relevantes do sistema foi abaixo de $1,6 \%$.

\section{Análise dos resultados de simulação do cenário base}

Na Figura 3, podem-se observar as relações entre a capacidade máxima de produção (CMP) e a previsão de demanda hídrica de cada sistema para o período de 2016 a 2030. Ainda, é possível analisar o comportamento de cada sistema e prever a ocorrência de colapsos, ou seja, os momentos em que haverá déficit de água.

Vê-se que os sistemas Catarina (CAT) (Figura 3B) e Vargem das Flores (VF) (Figura 3C) apresentam colapso desde o início do tempo de simulação (ano 2016), já que as demandas hídricas atendidas se igualam às capacidades máximas de produção de cada sistema desde o início. Esse fato implica que, a partir de 2016, a demanda hídrica total não será atendida por completo, ou o sistema passará a captar maior volume de água da sua respectiva bacia hidrográfica, comprometendo, assim, o curso natural de seus afluentes. Constata-se também tendência de colapso após o ano de 2030 nos demais sistemas que integram o Paraopeba, sendo eles Rio Manso (RM) e Serra Azul (SA) (Figura 3D), e no SIRV (Figura 3A). A tendência de colapso pode ser notada uma vez que as demandas hídricas de cada um desses sistemas chegam a 75,3, 79,8 e $87,6 \%$ das suas respectivas capacidades máximas de produção e em razão da existência de tendência de crescimento da demanda hídrica durante o período simulado. Nos demais sistemas, Barreiro (BAR) 
(Figura 3B), Ibirité (IB) e Morro Redondo (MR) (Figura $3 C$ ), é pouco provável que ocorra algum colapso nos próximos anos, pois as demandas apresentadas correspondem a apenas $26,1,39,9$ e $64,7 \%$ de suas respectivas capacidades máximas de produção no último ano da simulação.

O diagnóstico publicado em 2015 pela ANA relata que a COPASA possuía atendimento satisfatório da demanda de água da RMBH até aquele ano. Entretanto, para os anos seguintes, identificou-se a necessidade de investimentos em obras para o aproveitamento de novos mananciais ou para a adequação dos sistemas
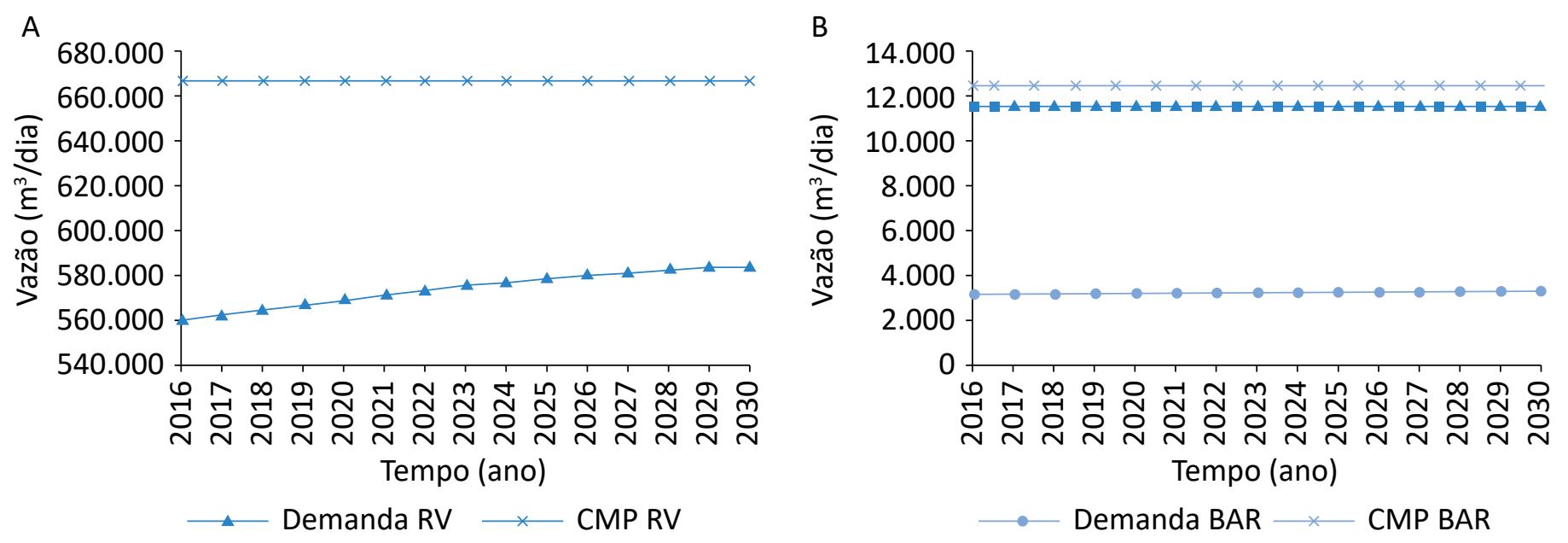

C $90.000_{7}$ 80.000

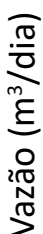

70.000

60.000

50.000

40.000

30.000

20.000

10.000

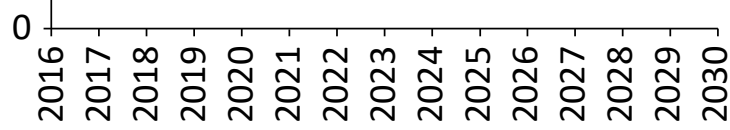

Tempo (ano)

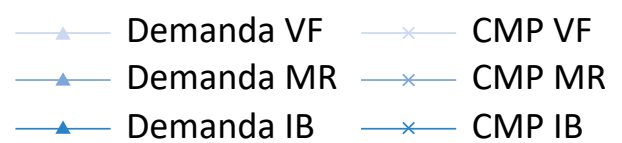

B $\longrightarrow$ Demanda BAR $\longrightarrow$ CMP BAR $\longrightarrow$ Demanda CAT $\longrightarrow$ CMP CAT

existentes, visando garantir o abastecimento satisfatório em algumas cidades da $\mathrm{RMBH}$. Os resultados da simulação apresentados corroboram com o relato deste diagnóstico, já que se podem verificar colapsos e tendências de colapsos em alguns sistemas de recursos hídricos responsáveis por atender à RMBH nos próximos anos.

Com o objetivo ainda de confrontar os resultados obtidos no presente estudo com a literatura, analisou-se a atualização parcial do Plano Diretor de Recursos Hídricos do Rio das Velhas (PDRH-RV) referente ao ano de 2015 e divulgada em 2017. O plano apresenta a criação

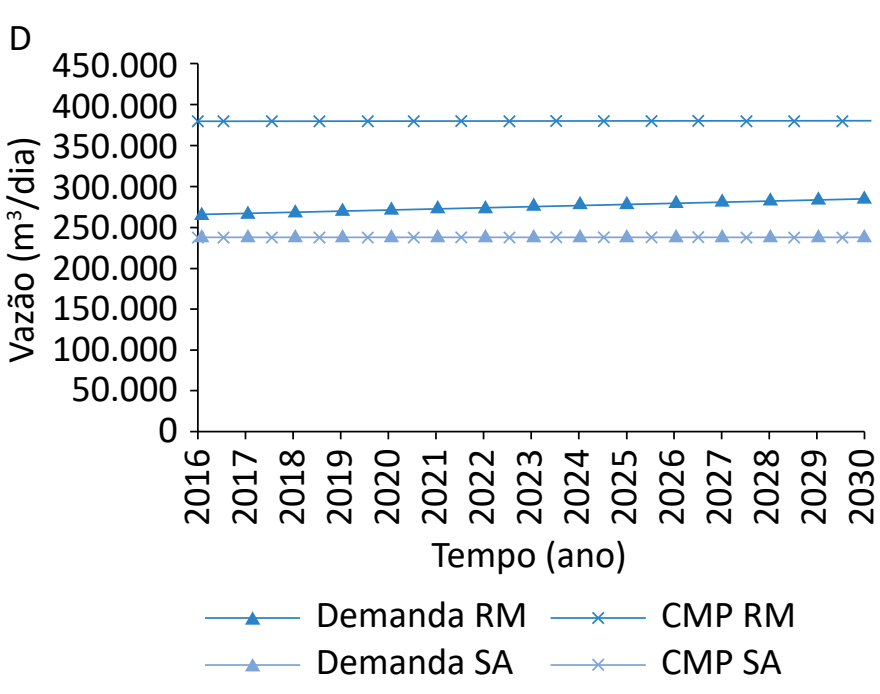

RV: Rio das Velhas; VF: Vargem das Flores; IB: Ibirité; MR: Morro Redondo; BAR: Barreiro; CAT: Catarina; RM: Rio Manso; SA: Serra Azul.

Figura 3 - Comparativo da capacidade máxima de produção (CMP) e da demanda hídrica dos sistemas Rio das Velhas (A), Barreiro e Catarina (B), lbirité, Morro Redondo e Vargem das Flores (C) e Rio Manso e Serra Azul (D) no cenário base. 
de quatro cenários para a bacia, no período entre 2015 e 2035, que visa antecipar a demanda, de forma que a gestão de recursos hídricos contribua para a conservação desses recursos e a racionalização do seu uso. A criação dos cenários teve por base uma análise realizada previamente que identificou as principais influências externas à bacia. Tais cenários se diferem quanto à dinâmica da atividade produtiva e à eficácia da gestão de recursos hídricos na bacia. Entre eles, avaliou-se que o cenário atual da bacia do Rio das Velhas corresponde ao denominado de Degradação de Recursos Hídricos, que combina a menor eficácia da gestão de recursos hídricos com o aumento da atividade produtiva demandante de água, apesar de essa gestão estar em um patamar mais próximo do ponto neutro do eixo e apontar para tendência de melhora em um ambiente de aumento da atividade produtiva demandante de água. Para cada cenário, foi feita a projeção de demanda hídrica no período proposto, tendo como horizontes para apresentação de resultados intermediários os anos de 2020, 2025 e 2030.

Sabendo que no PDRH-RV (COMITÊ DA BACIA HIDROGRÁFICA DO RIO DAS VELHAS, 2015) se considerou que $36,2 \%$ da demanda hídrica total da bacia é referente ao abastecimento urbano e que $71,73 \%$ deste é destinado a atender à $\mathrm{RMBH}$, as projeções de demanda hídrica para abastecimento urbano da $\mathrm{RMBH}$, de acordo com o estudo para os anos 2020, 2025 e 2030, são, respectivamente, $524.272 \mathrm{~m}^{3} /$ dia,
$571.919 \mathrm{~m}^{3} /$ dia e $620.525 \mathrm{~m}^{3} /$ dia no cenário Degradação de Recursos Hídricos. Por outro lado, as projeções de demanda hídrica no SIRV obtidas aqui são $553.008 \mathrm{~m}^{3} /$ dia em 2020, $561.805 \mathrm{~m}^{3} /$ dia em 2025 e $567.717 \mathrm{~m}^{3} /$ dia em 2030 .

Dessa maneira, a diferença relativa entre os resultados obtidos no PDRH-RV (COMITÊ DA BACIA HIDROGRÁFICA DO RIO DAS VELHAS, 2015) e no presente trabalho são de 5,48\% em 2020, 1,77\% em 2025 e $8,51 \%$ em 2030. Essa diferença pode ter ocorrido pelo fato de este estudo utilizar como base para o cálculo da projeção populacional dos municípios a metodologia empregada atualmente pelo IBGE, proposta por Madeira e Simões (1972), em que se entende o crescimento populacional do município proporcional ao crescimento populacional do estado em que ele está inserido, conforme descrito anteriormente. Já no PDRH-RV (COMITÊ DA BACIA HIDROGRÁFICA DO RIO DAS VELHAS, 2015), a metodologia aplicada para o cálculo da projeção populacional dos municípios toma como base uma unidade territorial menor, representada pelos setores censitários do IBGE. Com diferença relativa média da projeção de demanda hídrica para 2020, 2025 e 2030 de 5,25\% entre os dois estudos, pode-se afirmar que os resultados apresentados estão em consonância e mostram em suas projeções a mesma tendência de crescimento da demanda hídrica no SIRV para o período simulado.

\section{Previsão do local de colapso no sistema integrado da Região Metropolitana de Belo Horizonte}

Conforme apresentado anteriormente, existe a previsão de colapso em dois sistemas, Catarina e Vargem das Flores, no período simulado. Na Tabela 1, pode-se observar em que ponto da rede de distribuição do Sistema Catarina poderá ocorrer o colapso. Ou seja, é possível verificar a partir de qual cidade haverá déficit de água, considerando que a ordem da distribuição de água é a sequência física das cidades em relação às respectivas ETAs que as abastecem, conforme os diagramas de fluxo dos sistemas do modelo aqui proposto. Assim, verifica-se que a variável Cat Entrada 2 é menor do que a variável Demanda catBRU desde o ano 2016. Ou seja, o Sistema Catarina já está funcionando além do seu limite, e o local onde ocorre o seu déficit hídrico é a cidade de Brumadinho, que corresponde à segunda e última cidade atendida pelo sistema.
De acordo com o modelo desenvolvido para o Sistema Catarina, as variáveis Cat Entrada 1 e Cat Entrada 2 representam as ofertas do sistema para cidades específicas, nesse caso, Belo Horizonte e Brumadinho, respectivamente. Já as variáveis Demanda catBH e Demanda catBRU indicam os percentuais de demanda dessas cidades atendidos pelo Sistema Catarina. Vê-se que, após atender à demanda da primeira cidade do sistema, a oferta da segunda cidade nada mais é do que o balanço hídrico anterior a ela, ou seja, a oferta da cidade anterior menos a demanda da cidade anterior.

Assim como no Sistema Catarina, observou-se, por meio dos resultados da simulação, que o Sistema Vargem das Flores entra em colapso a partir do tempo inicial de simulação, ano 2016, na cidade de Contagem, deixando, 
portanto, de atender às demais cidades posteriores a ela, que são Pedro Leopoldo, Vespasiano e Santa Luzia.

Realizou-se extensa pesquisa na literatura a fim de comparar os resultados obtidos no presente trabalho com estudos similares, entretanto não foi encontrado um estudo que fizesse a previsão de possível local de colapso hídrico na RMBH. Dessa maneira, os resultados aqui apresentados não puderam ser confrontados com a literatura.

\section{Análise dos resultados de simulação do cenário 1: influência da redução} da capacidade máxima de produção de água na sustentabilidade do modelo

Para a construção do cenário 1, primeiramente, analisou-se a variação mensal do nível dos reservatórios do Sistema Paraopeba, mais significativo sistema integrado que atende à $\mathrm{RMBH}$, de janeiro de 2014 a março de 2017. O objetivo foi comparar o menor nível dos reservatórios desse sistema no período em relação ao nível médio dos reservatórios no ano de 2014 - ano base utilizado no Plano Municipal de Saneamento de Belo Horizonte (2015), de onde foi obtido o parâmetro captação máxima permitida usado no cenário base desse trabalho. Por meio dessa análise, constatou-se redução média no volume total dos reservatórios em $35,7 \%$. Para fins de simulação do cenário 1 , considerou-se, portanto, essa mesma redução máxima dos ní-

Tabela 1 - Local do colapso hídrico no Sistema Catarina.

\begin{tabular}{|c|c|c|c|c|}
\hline Ano & CAT Entrada 1 & Demanda catBH & CAT Entrada 2 & Demanda catBRU \\
\hline 2016 & 10,89 & 6,12 & 4,77 & 5,59 \\
\hline 2017 & 10,89 & 6,14 & 4,75 & 5,66 \\
\hline 2018 & 10,89 & 6,16 & 4,73 & 5,73 \\
\hline 2019 & 10,89 & 6,18 & 4,71 & 5,79 \\
\hline 2020 & 10,89 & 6,20 & 4,69 & 5,85 \\
\hline 2021 & 10,89 & 6,21 & 4,68 & 5,91 \\
\hline 2022 & 10,89 & 6,23 & 4,66 & 5,96 \\
\hline 2023 & 10,89 & 6,25 & 4,65 & 6,01 \\
\hline 2024 & 10,89 & 6,27 & 4,63 & 6,06 \\
\hline 2025 & 10,89 & 6,28 & 4,62 & 6,10 \\
\hline 2026 & 10,89 & 6,29 & 4,60 & 6,14 \\
\hline 2027 & 10,89 & 6,3 & 4,59 & 6,18 \\
\hline 2028 & 10,89 & 6,31 & 4,58 & 6,21 \\
\hline 2029 & 10,89 & 6,32 & 4,57 & 6,25 \\
\hline 2030 & 10,89 & 6,33 & 4,57 & 6,27 \\
\hline
\end{tabular}

CAT: Catarina; catBH: Catarina-Belo Horizonte; catBRU: Catarina-Brumadinho. 
veis dos reservatórios do Sistema Paraopeba na capacidade máxima de produção de todos os oito sistemas, mantendo as demais variáveis inalteradas no que tange às previstas no cenário base, no intuito de verificar o impacto dessa redução de oferta de água no sistema como um todo.

Com a redução de $35,7 \%$ da capacidade máxima de produção de cada sistema para o ano de 2014, pode-se observar, na Figura 4, que os sistemas Catarina

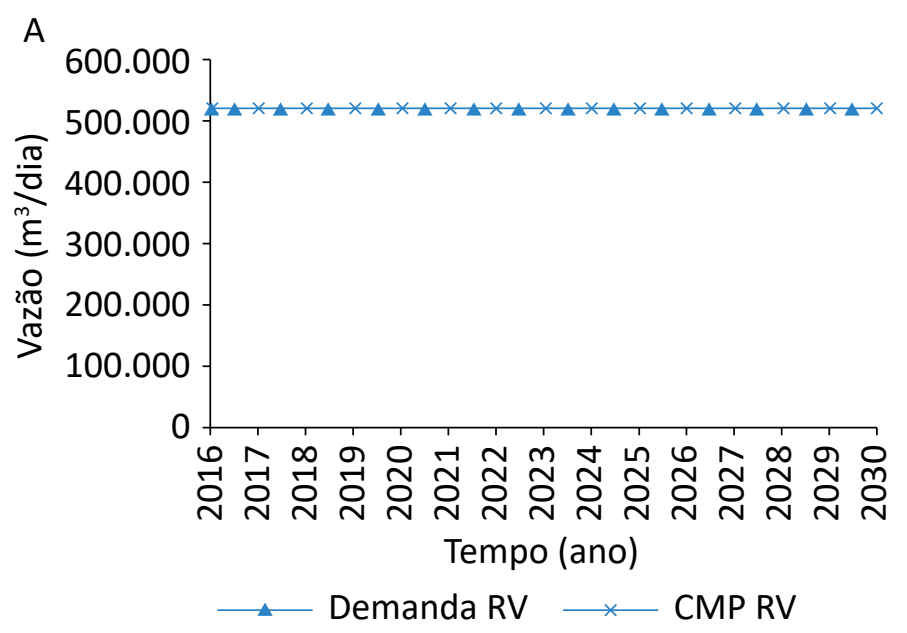

C

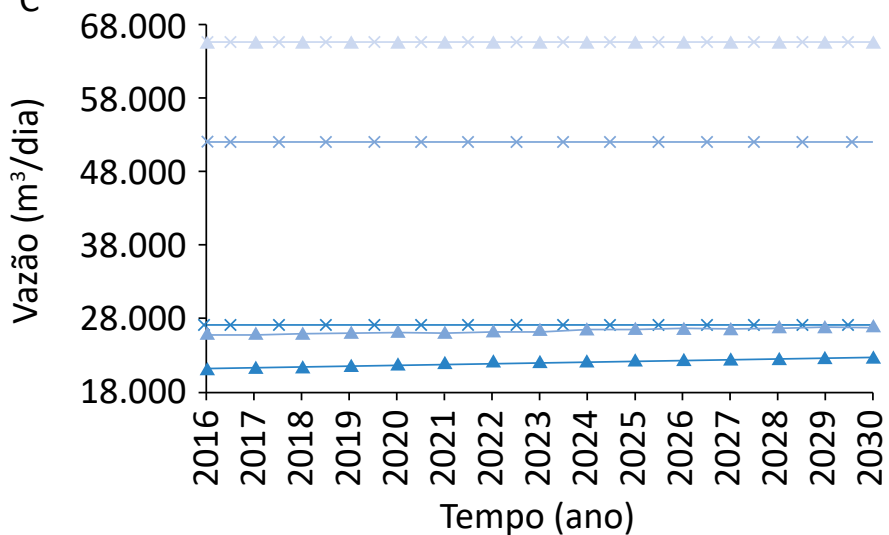

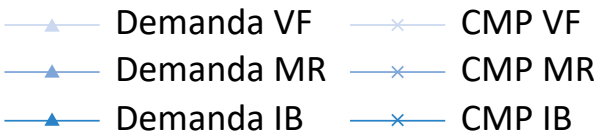

(CAT) (Figura 4B) e Vargem das Flores (VF) (Figura 4C), assim como no cenário base, apresentam colapso desde o início do tempo de simulação (ano 2016), uma vez que as demandas hídricas atendidas se igualam às capacidades máximas de produção de cada sistema desde o início.

Porém, além desses dois sistemas, percebe-se que os sistemas Rio das Velhas (RV) (Figura 4A), Serra Azul (SA) (Figura 4D), Rio Manso (RM) (Figura 4D) e Ibirité (IB)
B

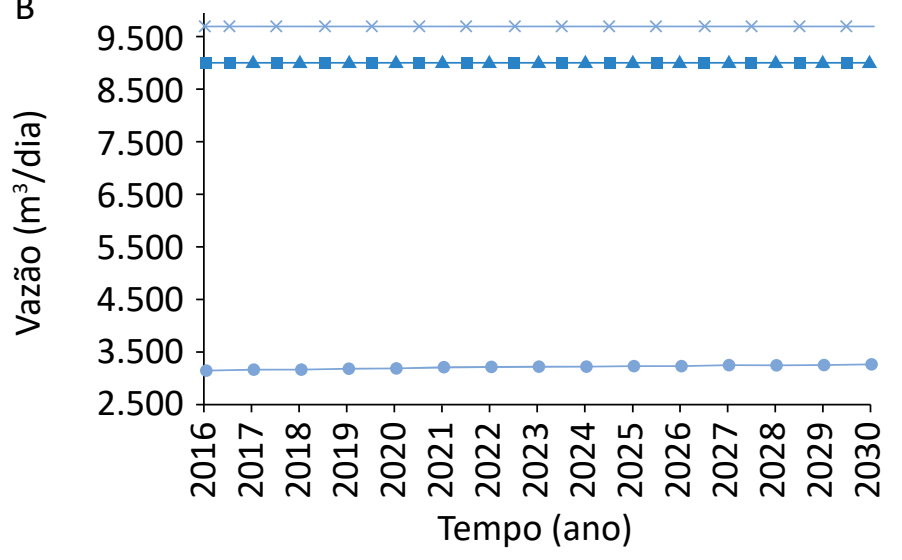

$\longrightarrow$ Demanda BAR $\longrightarrow$ CMP BAR

$\longrightarrow$ Demanda CAT $\longrightarrow$ CMP CAT

D

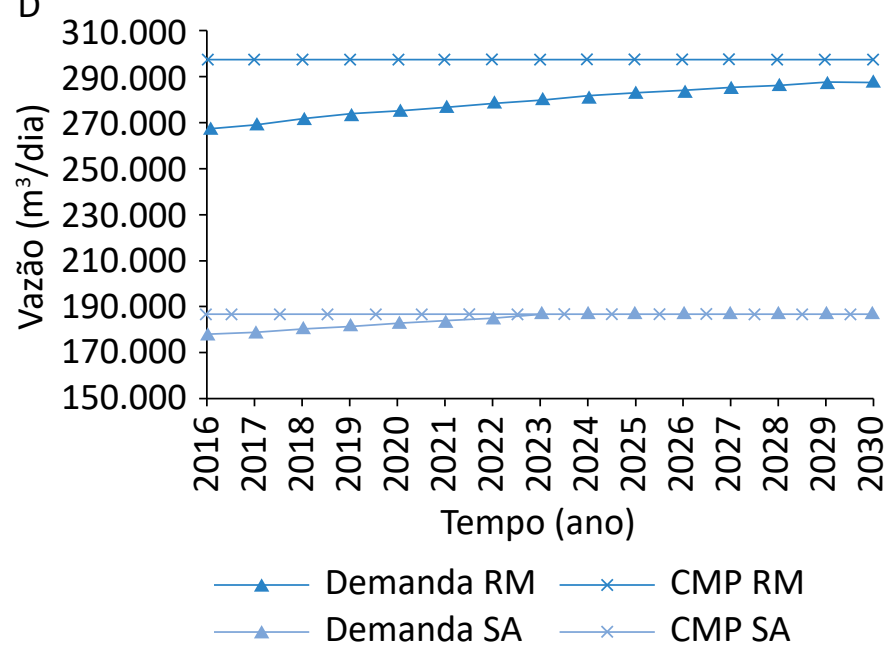

RV: Rio das Velhas; VF: Vargem das Flores; IB: Ibirité; MR: Morro Redondo; BAR: Barreiro; CAT: Catarina; RM: Rio Manso; SA: Serra Azul. Figura 4 - Comparativo da capacidade máxima de produção (CMP) e demanda hídrica dos sistemas Rio das Velhas (A), Barreiro e Catarina (B), Ibirité, Morro Redondo e Vargem das Flores (C) e Rio Manso e Serra Azul (D) no cenário 1. 
(Figura 4C) também entraram em colapso nesse cenário. De acordo com a figura 4, os três primeiros sistemas apontam colapso desde o início do tempo de simulação, e o Sistema IB apresenta-o a partir de 2021. Cabe destacar que, no cenário base, os sistemas RV, SA e RM já indicavam tendência de colapso após o ano de 2030.

\section{Cenário 1: previsão do local de colapso}

No Sistema Vargem das Flores, o colapso ocorre em Ribeirão das Neves a partir do ano de 2016. Por consequência, as cidades posteriores a ele ao colapso, Esmeraldas, Contagem, Pedro Leopoldo, Vespasiano e Santa Luzia, também não terão suas demandas atendidas pelo sistema. Comparando esse cenário ao cenário base, o local de colapso dá-se duas cidades antes do local de colapso do cenário base, que era Contagem.

No Sistema Catarina, o colapso ocorre em Belo Horizonte também a partir de 2016. Por consequência, Brumadinho, que é a cidade na sequência ao colapso, também não terá sua demanda atendida. Novamente, tem-se o local de colapso já na primeira cidade do sistema, ao contrário do local de colapso do cenário base, que foi apenas a segunda cidade atendida, Brumadinho.

Já no SIRV, tem-se o colapso em Belo Horizonte, a última cidade atendida, a partir do ano de 2016. Este sistema não havia entrado em colapso no cenário base, mas já apresentava tendência a colapsar após 2030.
Nos demais sistemas, Barreiro (BA) (Figura 4B) e Morro Redondo (MR) (Figura 4C), mesmo com a redução da oferta de água, é pouco provável que ocorra algum colapso nos próximos anos, pois as demandas exibidas correspondem a apenas 41,9 e $64,0 \%$ de suas respectivas capacidades máximas de produção no último ano da simulação.

No Sistema Serra Azul, o colapso é em Contagem, novamente a partir do ano de 2016. Assim, as cidades posteriores ao local do colapso, Pedro Leopoldo e Vespasiano, também não terão suas demandas atendidas. Da mesma forma que o SIRV, esse sistema não havia entrado em colapso no cenário base, mas já indicava tendência a colapsar após o ano de 2030.

Quanto ao Sistema Rio Manso, o colapso ocorre em Contagem também a partir do ano de 2016. Logo, as cidades posteriores ao colapso, Pedro Leopoldo e Vespasiano, também não terão suas demandas atendidas. Novamente, assim como nos sistemas Rio das Velhas e Serra Azul, esse sistema não havia entrado em colapso no cenário base, mas já demonstrava tendência a colapso após o período simulado.

Por último, no Sistema Ibirité, o colapso ocorre em Ibirité, que é a última cidade atendida. Diferentemente dos anteriores, ele entra em colapso apenas a partir do ano de 2021. Destaca-se que o Ibirité, de acordo com o cenário base, apresentava pequena probabilidade de ocorrência de algum colapso nos próximos anos.

\section{Análise dos resultados de simulação do cenário 2: influência da redução do consumo médio per capita de água na sustentabilidade do modelo}

Para a construção e simulação do cenário 2 , verificou-se, primeiramente, o histórico do consumo per capita dos últimos anos disponibilizados pelo SNIS (2013 a 2015) das quatro maiores cidades da RMBH atendidas pelo sistema: Belo Horizonte, Contagem, Betim e Ribeirão das Neves. Por meio dessa verificação, constatou-se que houve redução média do consumo per capita nos três últimos anos nas quatro cidades de 6,4\% anuais. Considerando essa tendência, reduziu-se, para simular o cenário 2 , o consumo per capita em todas as cidades do sistema em $6,4 \%$, a fim de analisar o impacto dessa redução no sistema como um todo.
Nesse cenário, apresenta-se apenas o comportamento dos sistemas que exibiram colapso no cenário base visando observar se eles sairiam dessa situação com a redução proposta, uma vez que a diminuição do consumo per capita nos demais sistemas aliviou ainda mais seus balanços hídricos, favorecendo positivamente o atendimento da demanda. Portanto, nesses sistemas não houve a possibilidade de colapso hídrico e, por isso, seus resultados não serão apresentados.

Conforme a Figura 5, os sistemas Catarina (CAT) (Figura 5A) e Vargem das Flores (VF) (Figura 5B) continuam apresentando colapso desde 2016, assim como no cenário base. 
A

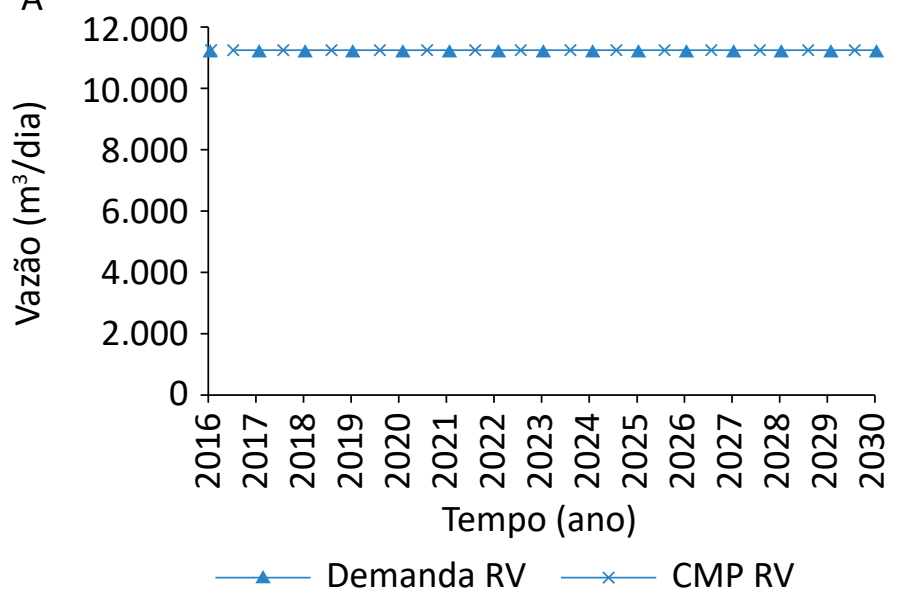

B

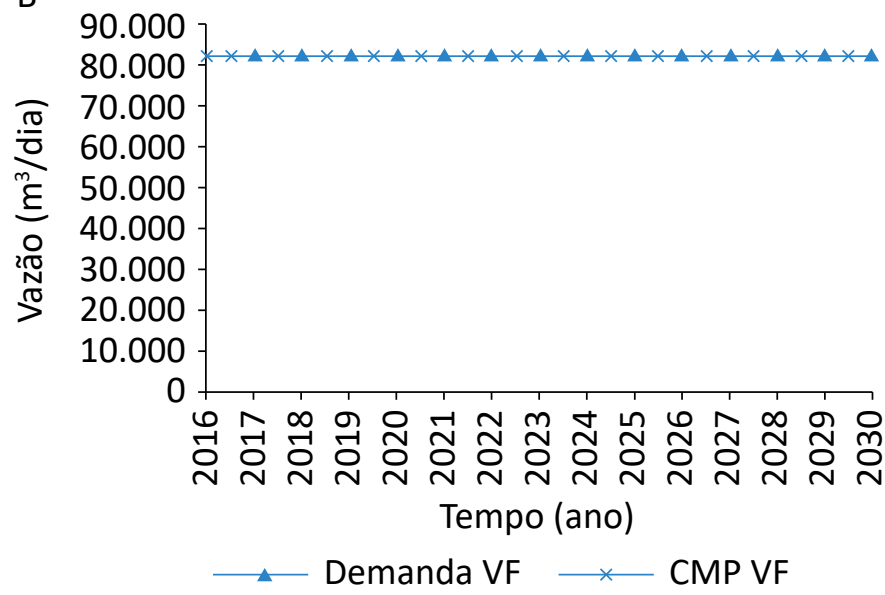

Figura 5 - Comparativo da capacidade máxima de produção (CMP) e demanda hídrica dos sistemas (A) Catarina (CAT) e (B) Vargem das Flores (VF) no cenário 2.

\section{Cenário 2: previsão do local de colapso}

No Sistema Vargem das Flores, assim como no cenário base, o colapso continua ocorrendo em Contagem a partir do ano de 2016. Dessa maneira, as cidades posteriores ao colapso, Pedro Leopoldo, Vespasiano e Santa Luzia, também não terão suas demandas atendidas.
Por sua vez, no Sistema Catarina, o colapso continua sendo em Brumadinho, último município atendido por esse sistema, também a partir do ano de 2016.

\section{Análise dos índices de sustentabilidade em todos os cenários}

Na Figura 6, apresenta-se o IS proposto por XU et al. (2002) e calculado para os oito sistemas integrados da RMBH no período de 2016 a 2030 para todos os cenários. No cenário base, observa-se que os IS dos sistemas Vargem das Flores (VF), Catarina (CAT) e Rio das Velhas (RV) se encontram abaixo do limite de sustentabilidade, que é 0,2 . De acordo com a previsão obtida, é possível constatar que o IS do Sistema Serra Azul (SA) atingirá o limite de 0,2 em 2029 e o IS do Sistema Rio Manso (RM) chegará a 0,25 em 2030. Nos demais, percebe-se que não há indicação da possibilidade de estresse hídrico.

No cenário 1, os sistemas VF, CAT e RV continuam apresentando IS com valores abaixo do limite de sustentabilidade. Além deles, o Sistema SA, que apresentou IS abaixo do limite no cenário base apenas no ano 2029, nesse cenário passou a apresentar IS abaixo do limite desde o tempo inicial de simulação.
Adicionalmente, nota-se que o Sistema RM, que no cenário base demonstrou tendência a atingir o limite IS (igual a 0,25 em 2030), agora também fica abaixo do limite desde o tempo inicial de simulação. Já o Sistema Ibirité, nesse cenário, apresentou IS abaixo do limite desde 2016.

Os demais sistemas, Barreiro e Morro Redondo, não apresentaram IS abaixo de 0,2 . No cenário 2, os sistemas VF e CAT continuam com valores de IS abaixo do limite de sustentabilidade, 0,2. O Sistema RV, por sua vez, não se encontra mais na área de tensão hídrica, diferentemente do cenário base. Já o Sistema SA, assim como no cenário base, apresentou IS abaixo do limite apenas no ano 2029. O Sistema RM também teve comportamento similar, com tendência a atingir o limite IS logo após o período de simulação (IS igual a 0,25 em 2030). Nos demais, observa-se que não há indicação de possibilidade de estresse hídrico. 
A

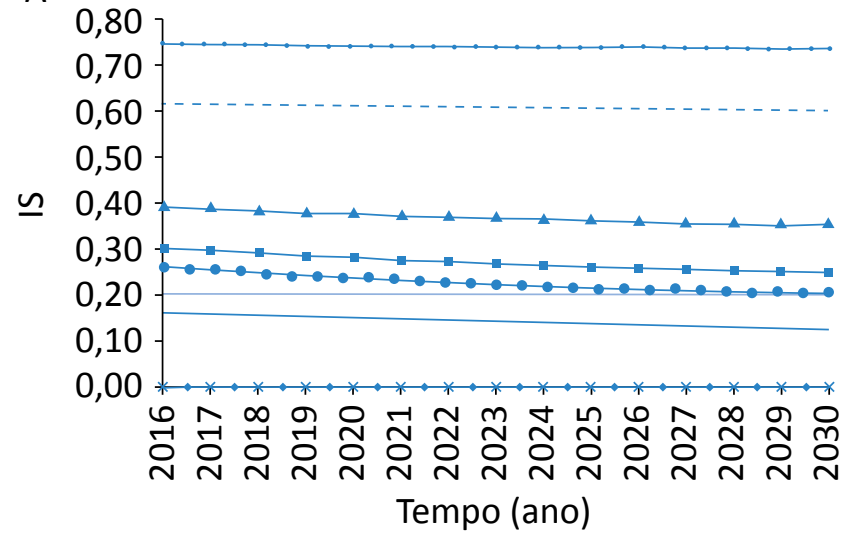

C

$\simeq$

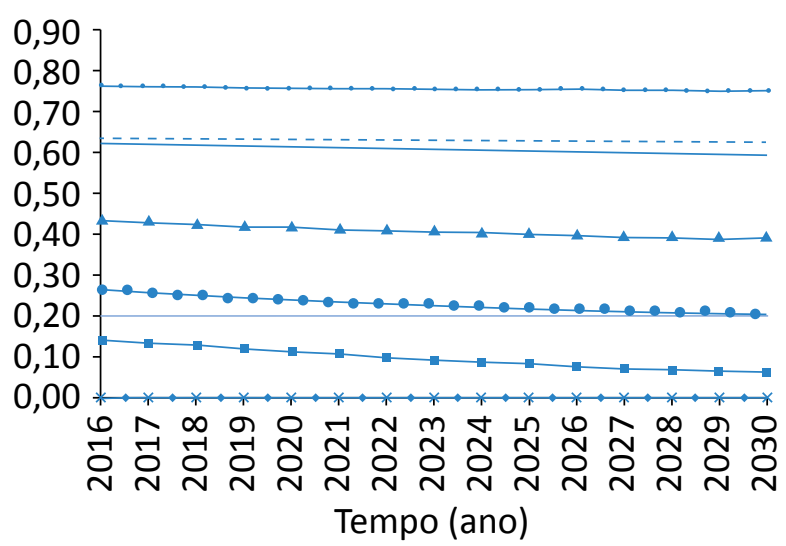

B

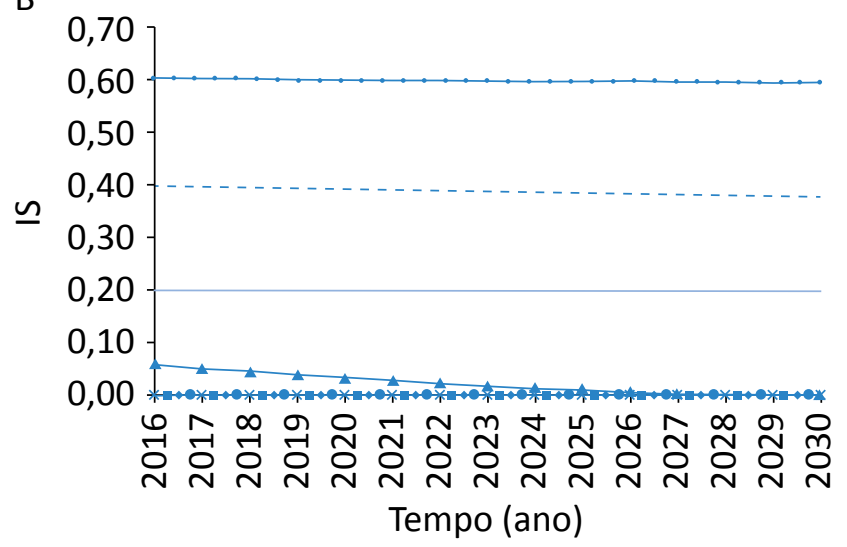

BAR: Barreiro; CAT: Catarina; RV: Rio das Velhas; SA: Serra Azul; VF: Vargem das Flores; IB: Ibirité; MR: Morro Redondo; RM: Rio Manso.

Figura 6 - Comparação entre os índices de sustentabilidade (IS) dos sistemas integrados da Região Metropolitana de Belo Horizonte e seu limite de sustentabilidade de acordo com os cenários: (A) cenário base; (B) cenário $1 ;$ (C) cenário 2.

\section{CONCLUSÃO}

Os resultados obtidos por meio das simulações e análises dos cenários propostos permitem concluir que o estudo do abastecimento hídrico por meio de simulação utilizando a técnica de DS foi viável e relevante para identificar possíveis locais e momentos de colapsos hídricos. Dessa forma, podeauxiliar as tomadas de decisão referentes à gestão dos recursos hídricos do sistema integrado da RMBH.

É possível concluir também que o sistema integrado de abastecimento hídrico da RMBH já opera abaixo da necessidade local desde 2016 em dois subsistemas, Vargem das Flores e Catarina, em todos os cenários examinados. Isso pode ser constatado pelos resultados da simulação e pelo cálculo do IS, que se mostrou abaixo do limite de 0,2.
Portanto, esses dois sistemas estão em condição vulnerável, apresentando estresse hídrico. Apesar da pequena representatividade desses sistemas no total de oferta hídrica da RMBH, sugere-se que ambos sejam monitorados e geridos com mais atenção, a fim de evitar problemas relacionados à escassez de água na região.

Além disso, constatou-se que os subsistemas Rio Manso, Rio das Velhas e Serra Azul são passíveis de colapso e devem ser criteriosamente analisados, uma vez que representam $86 \%$ do abastecimento total da $\mathrm{RMBH}$. Para garantir o bom desempenho desses subsistemas a longo prazo, recomenda-se a realização de medidas preventivas como educação da população sobre consumo consciente de água, mais fiscalização visando 
reduzir a poluição dos afluentes, a elaboração de um projeto eficaz para reduzir as perdas na distribuição, entre outras.

Quanto aos demais subsistemas, Barreiro e Morro Redondo encontram-se em condição estável nos três cenários simulados. Já o subsistema Ibirité ficou abaixo do limite do IS apenas no cenário 1. Mesmo esses subsistemas alcançando resultados mais otimistas, precisam ser monitorados e geridos para garantir que variáveis externas ou cenários imprevistos não comprometam seus comportamentos.

Assim, viu-se que o principal diferencial proporcionado pelo modelo proposto neste trabalho foi a utilização da técnica de DS, não apenas para identificar os momentos de colapso hídrico, mas também para identificar os locais em que esses colapsos ocorrem.

\section{REFERÊNCIAS}

AGÊNCIA NACIONAL DE ÁGUAS (ANA). Atlas de abastecimento urbano de água. Disponível em: <http://atlas.ana.gov. br/Atlas/forms/analise/Geral.aspx?est=8>. Acesso em: 25 mar. 2016.

AYALA, G. T.; OKUMURA, M.; KIM, J. Water Demand and Supply Balance by Using Urban Spatial Development Model and System Dynamics. Proceedings of Infrastructure Planning, v. 50, n. 297, 2014. CD-ROM.

BRASIL. Ministério das Cidades. Sistema Nacional de Informações sobre Saneamento: informações e indicadores municipais consolidados. Disponível em: <http://app.cidades.gov.br/serieHistorica/>. Acesso em: 10 abr. 2016.

CHEN, Z.; WEI, S. Application of System Dynamics to Water Security Research. Water Resources Management, v. 28, n. 2, p. 287-300, jan. 2014. https://doi.org/10.1007/s11269-013-0496-8

COMITÊ DA BACIA HIDROGRÁFICA DO RIO DAS VELHAS. Plano Diretor de Recursos Hídricos da Bacia Hidrográfica do Rio das Velhas. Belo Horizonte, 2015.

COMPANHIA DE SANEAMENTO DE MINAS GERAIS (COPASA). Informações sobre o abastecimento. Disponível em: <http://www.copasa.com.br/wps/portal/internet/imprensa/noticias/informacoes-sobre-abastecimento $>$. Acesso em: 15 abr. 2016.

DOMINGOS, J. C.; POLITANO, P. R.; PEREIRA, N. A. Modelo de dinâmica de sistemas para o processo de S\&OP ampliado. Gestão e Produção, São Carlos, v. 22, n. 4, p. 755-788, jan. 2015. http://dx.doi.org/10.1590/0104-530X1702-14

FEIL, A. A.; TUCCI, C. Consumo eficiente, conservação e características sociodemográficas que influenciam no consumo de água. Revista Brasileira de Ciências Ambientais, Rio Grande do Sul, n. 34, dez. 2014.

FERNANDÉZ, N.; SUÁREZ, C. A.; PÉREZ, E.A. Modelación y Simulación Dinámica para la Gestión de Caudales en la Cuenca Alta del Río Pamplonita: Un Balance Hídrico de Consumo. Bistua, Pamplona, v. 5, n. 2, p. 80-96, jul. 2007.

GARCIA, J. M. Theory and practical exercises of system dynamics. Barcelona: Juan Martín Garcia, 2003. 294 p.

GOULART, R. J.; ALVES, J. M.;SOBRINHO, R. P.; ROMEIRO, A. R. Cidades sustentáveis: o manejo urbano de recursos hídricos. In: ENCONTRO DA SOCIEDADE BRASILEIRA DE ECONOMIA ECOLÓGICA, 9., 2011, Brasília. Estudo da disponibilidade hídrica das bacias PCJ utilizando dinâmica de sistemas. Disponível em: <http://docplayer.com.br/76489504-Estudo-dadisponibilidade-hidrica-das-bacias-pcj-utilizando-dinamica-de-sistemas.html> Acesso em: 7 out. 2015.

HOVI, V.; HUTTUNEN, M.; KARPPINEN, I.; PÄTTIKANGAS, T.; NIEMISTÖ, H.; KARVONEN, L.; KALLIO, S.; TUURI, S.; YLÄ-OUTINEN, V. Integrated transient simulation of a BFB boiler with CFD models for the BFB furnace and dynamic system models for the steam cycle and boiler operation. Energy Procedia, v. 120, p. 508-515, jul. 2017. https://doi. org/10.1016/j.egypro.2017.07.186

INSTITUTO BRASILEIRO DE GEOGRAFIA E ESTATÍSTICA. Censo Demográfico de 2000. Disponível em: <https://ww2.ibge. gov.br/home/estatistica/populacao/censo2000/>. Acesso em: 12 de fevereiro de 2016. 
INSTITUTO BRASILEIRO DE GEOGRAFIA E ESTATÍSTICA (IBGE). Indicadores sociais de população. 2010. Disponível em: <http://www.ibge.gov.br/home/mapa_site/mapa_site.php\#populacao>. Acesso em: 20 mar. 2016.

KELMAN, J. Water supply to the two largest Brazilian metropolitan regions. Aquatic Procedia, v. 5, p. 13-21, out. 2015. https://doi.org/10.1016/j.aqpro.2015.10.004

LI, X.; MADNICK, S. E. Understanding the Dynamics of Service-Oriented Architecture Implementation. Journal of Management Information Systems, v. 32, n. 2, p. 104-133, jul. 2015. https://doi.org/10.1080/07421222.2015.1063284

MADEIRA, J. L.; SIMÕES, C. C. S. Estimativas preliminares da população urbana e rural segundo as unidades da Federação de 1960/1980 por uma nova metodologia. Revista Brasileira de Estatística, v. 33, n. 129, p. 3-11, jan./mar. 1972.

MULA, J.; BOLARIN, C.; DÍAZ-MADROÑERO, M.;CARPIO, K. M. A system dynamics model for the supply chain procurement transport problem: comparing spreadsheets, fuzzy programming and simulation approaches. International Journal of Production Research, v. 51, n. 13, p. 4087-4104, jan. 2013. https://doi.org/10.1080/00207543.2013.774487

QI, P.; CHEN, Y. Simulation and Prediction of Excellent Students Based on System Dynamics. Applied Mechanics and Materials, v. 713, p. 1914-1917, 2015. https://doi.org/10.4028/www.scientific.net/AMM.713-715.1914

RODRIGUEZ, F. A. Os caminhos das águas. Agroanalysis, v. 18, n. 22, p. 23-26, mar. 1998.

SALIM, N. A.; OTHMAN, M. M.; MUSIRIN, I.; SERWAN, M.; BUSAN, S. Risk assessment of dynamic system cascading collapse for determining the sensitive transmission lines and severity of total loading conditions. Reliability Engineering \& System Safety, v. 157, p. 113-128, 2016. http://dx.doi.org/10.1016/j.ress.2016.08.002

SÃO PAULO (Estado). Secretaria de Saneamento e Energia. Plano Municipal de Saneamento Básico. São Paulo: Programa de fortalecimento dos instrumentos de planejamento do setor de saneamento, 2009.

SIMONOVIC, S. P.; RAJASEKARAM, V. Integrated Analyses of Canada's Water Resources: A System Dynamics Approach. Canadian Water Resources Journal, v. 29, n. 4, p. 223-250, out. 2004. https://doi.org/10.4296/cwrj223

VENTANA SYSTEMS. Vensim Simulation Software. Disponível em: <http://www.vensim.com>. Acesso em: mar. 2016.

WANG, B.; LI, W.; HUANG, G. H.; LIU, L.; LI, J.; LI, Y. Urban water resources allocation under the uncertainties of water supply and demand: a case study of Urumqi, China. Environmental Earth Sciences, v. 74, p. 3543-3557, abr. 2015. https://doi.org/10.1007/s12665-015-4420-9

WANG, K.; DAVIES, E. G. R. Municipal water planning and management with an end-use based simulation model. Environmental Modelling \& Software, v. 101, p. 204-217, abr. 2018. https://doi.org/10.1016/j.envsoft.2017.12.024

WEI, T.; LOU, I.; YANG, Z.; LI, Y. A system dynamics urban water management model for Macau, China. Journal of Environmental Sciences, v. 50, p. 117-126, out. 2016. https://doi.org/10.1016/j.jes.2016.06.034

YANG, S.; GUO, H.; LI, Y.; LIU, J. L. The application of system dynamics model of city water demand forecasting. Applied Mechanics and Materials, v. 535, p. 440-445, fev. 2014. https://doi.org/10.4028/www.scientific.net/AMM.535.440

XU, Z. X.; TAKEUSHI, K.; ISHIDAIRA, H.; ZHANG, X. W. Sustainability Analysis for Yellow River Water Resources Using the System Dynamics Approach. Water Resources Management, v. 16, p. 239-261, maio 2002. https://doi. org/10.1023/A:1020206826669 